\title{
A ECOALFABETIZAÇÃO NO ENSINO JURÍDICO: novos desafios á consciência ambiental $^{1}$
}

\section{ECOLITERACY IN LAW TEACHING: new challenges to environmental awareness}

\author{
Maria Cláudia Silva Antunes de Souza ${ }^{2}$ \\ Camila Monteiro Santos Stohrer ${ }^{3}$
}

\section{RESUMO}

O ensino superior está estruturado, no Brasil, para que cada disciplina ocupe seu espaço específico dentro do currículo rígido. O presente artigo visa analisar o panorama atual do ensino jurídico no país e discorrer sobre a possibilidade de flexibilização do currículo. Assim, o objetivo geral é identificar se a Ecoalfabetização pode contribuir para elaborar um novo paradigma de ensino para a sustentabilidade através de cidadãos ambientalmente conscientes. Como objetivos específicos descrever o ensino jurídico no Brasil e conceituar a ecoalfabetização, sustentabilidade e consciência ambiental. A metodologia emprega técnicas da revisão bibliográfica e do fichamento, através da base lógica indutiva.

Palavras-chave: Consciência Ambiental. Ecoalfabetização. Ensino Jurídico. Sustentabilidade.

ABSTRACT: Graduation in Brazil is structured so that each Subject occupies its space within what is called rigid curriculum. The present article aims to analyze current situation of Law graduation in

\footnotetext{
${ }^{1}$ Este estudo foi objeto de discussão no XXVI Congresso Nacional do CONPED, São Luís - Maranhão.

${ }^{2}$ Doutora e Mestre em Derecho Ambiental y de la Sostenibilidad pela Universidade de Alicante - Espanha. Mestre em Ciência Jurídica pela Universidade do Vale do Itajaí - UNIVALI. Professora no Programa de Pós-Graduação Stricto Sensu em Ciência Jurídica, nos cursos de Doutorado e Mestrado em Ciência Jurídica, e na Graduação no Curso de Direito da Universidade do Vale do Itajaí - UNIVALI. Coordenadora do Grupo de Pesquisa "Estado, Direito Ambiental, Transnacionalidade e Sustentabilidade" cadastrado no CNPq/EDATS/UNIVALI. Coordenadora do Projeto de pesquisa aprovado no CNPq intitulado: “Análise comparada dos limites e das possibilidades da avaliação ambiental estratégica e sua efetivação com vistas a contribuir para uma melhor gestão ambiental da atividade portuária no Brasil e na Espanha”. E-mail: mclaudia@univali.br. Orcid: https://orcid.org/0000-0002-8118-1071.

${ }^{3}$ Doutora em Derecho Ambiental y de la Sostenibilidad pela Universidad de Alicante - Espanha. Mestre em Ciência Jurídica pela Universidade do Vale do Itajaí - UNIVALI.. Pesquisadora do Grupo de Pesquisa e Extensão Paideia, cadastrado no CNPq, linha de pesquisa em Direito Ambiental e Sustentabilidade. Professora de Direito Ambiental na Universidade do Vale do Itajaí, Campus Itajaí. Advogada. E-mail: camila.stohrer@univali.br
} 
Brazil, and to discuss the possibility of making curriculum flexible to raise students' awareness. The main goal of the article is to identify if Capra's Ecoliteracy can contribute in creating a new teaching paradigm towards a more sustainable world through environmentally conscious citizens. Specific goals include presenting situation of Law graduation in Brazil, and defining Ecoliteracy and environmental awareness. Bibliographical review, book report techniques and logical inductive base were used.

Key-words: Environmental Consciousness. Ecoliteracy. Law Education. Sustainability.

\section{INTRODUÇÃO}

O presente artigo tem como objeto o analise do panorama atual do ensino jurídico no país e discorrer sobre a possibilidade de flexibilização do currículo. Assim, o objetivo geral é identificar se a Ecoalfabetização pode contribuir para elaborar um novo paradigma de ensino para a sustentabilidade através de cidadãos ambientalmente conscientes. Como objetivos específicos descrever o ensino jurídico no Brasil e conceituar a ecoalfabetização, sustentabilidade e consciência ambiental. Justifica-se o estudo diante da necessidade latente de uma mudança significativa no modo de ensinar o Direito com vistas ao efetivo desenvolvimento da cidadania é a inquietude que dá azo ao presente trabalho.

O ensino jurídico tem sido realizado de maneira compartimentada, impedindo ao acadêmico uma visão sistêmica das disciplinas que lhe são apresentadas ao longo dos cinco anos que está cursando o ensino superior.

Uma preocupação excessiva com os resultados em concursos públicos e no Exame da Ordem dos Advogados do Brasil, levou a uma verdadeira reestruturação do currículo das faculdades de Direito com vistas à aprovação do acadêmico, transformando grande parte do ensino jurídico em “o que cai" e o que "não cai" no Exame da OAB.

A missão dos cursos de Direito, no entanto, deve estar alinhada com o perfil profissional que desejam formar, e este perfil, por sua vez, está previsto nas regulamentações específicas sobre o ensino jurídico.

Para além da formação técnico-jurídica (igualmente essencial, destaca-se), o estudo de disciplinas como Filosofia, Sociologia e Antropologia permite ao acadêmico o desenvolvimento de sua autonomia enquanto estudante, propiciando o aprimoramento de seu senso crítico. 
A educação ambiental também possui papel importante na formação do acadêmico, posto que se destina à formação de uma consciência para com a necessidade de preservação do meio ambiente, o qual, por sua vez, transcende questões ecológicas e compreende todos os locais onde haja vida.

Por este motivo, o problema da pesquisa é identificar de que forma o conceito de Alfabetização Ecológica desenvolvido por Fritjof Capra poderia contribuir na reestruturação do ensino jurídico? O cidadão ecologicamente consciente e responsável contribuirá para efetivação do novo paradigma da sustentabilidade?

Para tanto, o trabalho foi estruturado de forma a descrever a realidade atual do ensino jurídico no Brasil, e, posteriormente, discutir a necessidade do resgate de valores sociais na condução do trabalho docente. Por fim, conceitua-se a Alfabetização Ecológica e traça-se um paralelo de forma a identificar sua possibilidade de contribuição no ensino superior, considerando-se que foi originalmente cunhada para a educação básica.

$\mathrm{O}$ artigo foi confeccionado mediante aplicação do método indutivo, acionando-se as técnicas do referente e da revisão bibliográfica ${ }^{4}$.

\section{A REALIDADE DO ENSINO JURÍDICO NO BRASIL}

A formação do profissional de Direito é a preocupação e tema central deste trabalho. O ensino jurídico no Brasil vem sendo trabalhado através de um currículo rígido, o qual termina por minimizar a criação de uma consciência mais ampla do fenômeno jurídico. O currículo rígido, por sua vez, é reflexo do engessamento do ensino no país desde longa data, e consiste na segmentação do conhecimento, de forma que as diferentes áreas de estudo não são trabalhadas pelos docentes de forma a promover sua análise sistêmica.

Não obstante, sabe-se que, a partir dos estudos da Política Jurídica, o Direito existe para suprir as necessidades da sociedade, e precisa ser trabalhado de forma a solucionar os problemas concretos da vida real. Neste sentido, a interdisciplinaridade torna-se fator essencial de construção de conhecimento jurídico sólido, porquanto o futuro profissional do Direito deve dispor das ferramentas mentais para identificar a incidência de mais de uma área jurídica (ou mesmo área do conhecimento alheia ao Direito) para propor a solução mais adequada ao ser humano que se pretende atender.

\footnotetext{
4 “"...] pesquisar e identificar as partes de um fenômeno e colecioná-las de modo a ter uma percepção ou conclusão geral [...]". PASOLD, Cesar Luiz. Metodologia da pesquisa jurídica: teoria e prática. 11 ed. Florianópolis: Conceito Editorial; Millennium Editora, 2008.p. 86.
} 
Assim, a título de exemplo, pode-se citar a solução de questões ambientais, quando não é raro que estes problemas envolvam a necessidade de análises técnicas por profissionais das Ciências Exatas, a fim de se identificar a verdadeira extensão do dano, e apenas após este momento, promoverse a adequada responsabilização do poluidor, ajustada às dimensões da conduta que de fato praticou.

O mesmo pode ser observado nas causas de Direito de Família, quando a obtenção de uma mediação pode depender da atuação de profissionais da área da Psicologia, por exemplo, a fim de identificar o que de fato está por trás das negativas de conciliação. Um importante exemplo dessa interconexão na área específica do Direito de Família é a técnica da Constelação Familiar, a qual já vem sendo aplicada em tribunais do país e que é decorrente da Psicologia, tendo se convertido em um significativo instrumento não jurídico de solução de conflitos judiciais.

Tais exemplos permitiriam inferir que um ensino jurídico de qualidade, portanto, deve preparar o futuro profissional para esta interdisciplinaridade, para esta verdadeira sinergia de saberes. No entanto, o que se observa nos cursos de Direito é uma forte tendência a medir a qualidade do ensino com as temidas avaliações a que os alunos são submetidos. O Exame da Ordem dos Advogados do Brasil, por exemplo, tende a servir como termômetro do aproveitamento dos acadêmicos em relação ao conteúdo do curso.

Não se está a criticar a necessidade de uma formação técnico-profissional que habilite o acadêmico a atuar com precisão nas causas jurídicas em que venha atuar no futuro. Não obstante, o que se observa na prática é um verdadeiro direcionamento do conteúdo à feitura de testes, abandonando o desenvolvimento de capacidades como a interpretação de textos e conexão de conteúdos, as quais são cruciais para a atuação jurídica de qualidade.

O dilema que envolve o docente de Direito não difere do enfrentado pelos professores do Ensino Médio. Ambos são cobrados pelo resultado. Este resultado, contudo, advém de testes que não medem, de fato, o conhecimento adquirido pelos candidatos. Ao contrário disso, acabam por reduzir todo o esforço realizado durante anos a números.

A análise trazida por Holt (2006, p. 89), pode muito facilmente ser transportada para a realidade do docente do curso de Direito, mormente quanto a sua função de agente duplo, bastando que se leia "Exame da Ordem" no lugar de "prova decisiva":

a prestação de contas administrativa pressupõe que a administração não seja algo circunscrito aos gabinetes de pessoas usando terno e gravata: ela invade a vida profissional dos professores. E transforma os professores em agentes duplos. Como profissionais, eles desejam inspirar novas ideias nos alunos e fazer com que o curso satisfaça seus interesses. Mas, como empregados, eles são perseguidos por aquela prova decisiva da semana que vem. 
Diante deste cenário, a “[...]graduação em Direito acaba sendo constituída pelo estudo sistemático de dispositivos legais e dos macetes necessários para decorá-los. " (MORAIS DA ROSA, 2014). O curso de Direito, refém do sistema que ajudou a construir, termina por dar menos ênfase às disciplinas que são cruciais no desenvolvimento do senso crítico e na capacidade de análise do fenômeno jurídico para que o aluno possa quantificar, em números seu aproveitamento. Infelizmente, o ensino jurídico atual foi do “[...] bacharelismo (busca da formação jurídica como índice de prestígio social) ao concursismo (ambição de tornar-se uma engrenagem da máquina estatal)" (MORAIS DA ROSA, 2006).

Entretanto, é imperioso recordar, sempre, que a universidade é o lugar onde os acadêmicos devem desenvolver sua mente, em verdadeira continuação de sua formação escolar. Em que pese seja compreensível a necessidade de estabelecimento de critérios para a avaliação do aproveitamento em relação ao Curso de Direito, não parece adequado atribuir apenas números ao processo de ensino aprendizagem (HOLT, 2006, p.88).

Mesmo porque a regulamentação para o Curso de Direito decorre, dentre outros instrumentos, da Resolução 9/2004 do Conselho Nacional de Educação, e esta resolução, por sua vez, leva em conta a necessidade da formação humanística do profissional de Direito.

$\mathrm{O}$ artigo $3^{\circ}$ da referida Resolução discorre sobre a importância de uma sólida formação geral, possibilitando ao egresso o desenvolvimento da cidadania:

\footnotetext{
Art. $3^{\circ}$. O curso de graduação em Direito deverá assegurar, no perfil do graduando, sólida formação geral, humanística e axiológica, capacidade de análise, domínio de conceitos e da terminologia jurídica, adequada argumentação, interpretação e valorização dos fenômenos jurídicos e sociais, aliada a uma postura reflexiva e de visão crítica que fomente a capacidade e a aptidão para a aprendizagem autônoma e dinâmica, indispensável ao exercício da Ciência do Direito, da prestação da justiça e do desenvolvimento da cidadania.(grifou-se)
}

Já no artigo $4^{\circ}$, a Resolução estabelece as competências que devem ser desenvolvidas ao longo do curso para que o acadêmico se metamorfose em um profissional completo. Dentre as inúmeras atividades técnico-jurídicas, pontua-se o inciso VI, o qual prevê a "utilização de raciocínio jurídico, de argumentação, de persuasão e de reflexão crítica”.

O desenvolvimento da autonomia do acadêmico na condução de seus estudos é crucial para o desenvolvimento da competência destacada. O papel do docente universitário, portanto, deve ir além dos apelos do que será ou não objeto do Exame da Ordem. É necessário que o docente possibilite ao acadêmico o desenvolvimento da capacidade de raciocínio e reflexão crítica. 
O ensino jurídico não pode permanecer refém do modelo fast food de ensinar, no qual se procura obter o máximo de resultado (ilusório, efêmero) com o mínimo de esforço. Não é possível que a formação jurídica do profissional seja reduzida a resumos e materiais simplificados, considerando-se que o currículo do curso de Direito deve ir além do conteúdo cobrado em concursos públicos.

Sabe-se, contudo, que a estrutura curricular dos cursos de Direito contempla as disciplinas de caráter propedêutico, tais como Filosofia, Sociologia e Antropologia. Tal inclusão, destaca-se, decorre da própria resolução, a qual inclui tais disciplinas em um eixo de formação denominado

\title{
Fundamental:
}

\begin{abstract}
Art. $5^{\circ} \mathrm{O}$ curso de graduação em Direito deverá contemplar, em seu Projeto Pedagógico e em sua Organização Curricular, conteúdos e atividades que atendam aos seguintes eixos interligados de formação:

I - Eixo de Formação Fundamental, tem por objetivo integrar o estudante no campo, estabelecendo as relações do Direito com outras áreas do saber, abrangendo dentre outros, estudos que envolvam conteúdos essenciais sobre Antropologia, Ciência Política, Economia, Ética, Filosofia, História, Psicologia e Sociologia.
\end{abstract}

Não obstante, tais conteúdos se encontram encravados em uma grade que reflete o pensamento do currículo rígido, o qual não permite ao acadêmico visualizar a importância dos conceitos abordados no início do curso às disciplinas técnicas.

Parte da responsabilidade por essa falta de visualização, entretanto, decorre da própria postura dos docentes diante de sua disciplina. Muitos mestres terminam por compartimentar o conteúdo de sua cadeira, deixando de alinhá-la aos chamados temas transversais, em profunda resistência às políticas que se destinam a conscientizar o acadêmico quanto à amplitude de determinadas áreas do saber.

Está-se a falar, neste momento, principalmente das diretrizes estabelecidas pelo Conselho Nacional de Educação no que tange a Política Nacional de Educação Ambiental, instituída pela lei 9.795/1999, e regulamentada pelo Decreto 4.281/2002.

Os ditames dos instrumentos normativos apresentados são claros ao determinar que a educação ambiental deva ocorrer em todos os níveis de ensino, referendando, inclusive, o disposto no artigo 225 da Constituição Federal, o qual, em seu parágrafo $1^{\circ}$, discorre sobre as incumbências do Poder Público em matéria de proteção ambiental e estabelece, no inciso VI, que cabe a ele "promover a educação ambiental em todos os níveis de ensino e a conscientização pública para a preservação do meio ambiente". (grifou-se) 
A lei da Política, por sua vez, conceitua educação ambiental como “[...] ]os processos por meio dos quais o indivíduo e a coletividade constroem valores sociais, conhecimentos, habilidades, atitudes e competências voltadas para a conservação do meio ambiente, bem de uso comum do povo, essencial à sadia qualidade de vida e sua sustentabilidade."

Observa-se, portanto, a preocupação do constituinte e do legislador com a formação da cidadania também por intermédio da educação para a proteção do meio ambiente, o qual é essencial à sadia qualidade de vida.

Retomando-se o perfil que se espera do graduando de Direito, verifica-se a preocupação com a construção de sólidos conhecimentos jurídicos associados à formação da cidadania e à capacidade de solucionar conflitos em meio à sociedade.

Entretanto, apesar das diretrizes de que, sempre que possível, as disciplinas do curso de Direito devam contemplar os conceitos da preservação ambiental, em realidade os acadêmicos terminam por ter contato com o tema apenas na cadeira de Direito Ambiental, o que prejudica sua capacidade de compreensão da amplitude do tema.

Os valores sociais a que se refere a Política Nacional de Educação Ambiental devem ser resgatados nos bancos da graduação em Direito, de forma a possibilitar a formação de um profissional consciente, equilibrado e com conhecimento que ultrapasse a barreira da técnica jurídica, que tenha condições de se ver como parte da sociedade e que anseie melhorá-la constantemente.

Para tanto, é necessário resgatar valores e incorporá-los ao modo de ser do ensino jurídico, conforme se passa a tratar no próximo item.

\section{O SENSO DE PERTENCIMENTO E A FLEXIBILIZAÇÃo DOS VAlORES AMBIENTAIS NA SOCIEDADE}

Na obra Teia da Vida, Fritjof Capra (2006b) discorre acerca da teoria sistêmica, invocando e referendando a teoria de James Lovelock de que a Terra seria um organismo vivo (Gaia), e que todas as ações praticadas nela teriam consequências em nível sistêmico.

A sociedade global, entretanto, parece não ter se atentado para tal constatação. Hodiernamente, o que se vislumbra é a busca incessante pelo crescimento econômico, que, por sua vez, ocorre em grande monta com o uso dos recursos naturais. 
Esta postura de parcial cegueira diante das consequências do uso desmedido dos recursos naturais decorre, segundo Rolo May (1972), do valor da competição individual difundido desde o Renascimento (MAY, 1972, p. 42).

Tal valor propagou a ideia de que a luta pelo enriquecimento individual levaria a um ganho material para toda a sociedade em que a atividade produtiva estivesse inserida (MAY, 1972, P.42-42). Para o autor,

se há dois séculos passados, alguém quisesse criar uma fazenda em plena floresta virgem, nos limites da civilização, ou há cem anos possuísse um pequeno capital para iniciar um negócio, a filosofia do 'cada qual por si' teria feito apelo a todas as suas qualidades e resultaria em benefício para a comunidade. (MAY, 1972, p. 43)

Daniel Goleman (2009) explica que o amortecimento de nossa percepção para com a natureza termina por impedir nossa evolução na busca por alternativas ecologicamente adequadas à manutenção da vida no planeta:

\begin{abstract}
A vida moderna reduz essas habilidades e sabedoria; no início do século XXI, a sociedade perdeu o contato com o que talvez seja uma sensibilidade singular, essencial à nossa sobrevivência como espécie. As rotinas de nossa vida cotidiana estão totalmente desconectadas de seus impactos adversos no mundo a nosso redor; nossa mente coletiva tem pontos cegos que desconectam nossas atividades cotidianas das crises que essas mesmas atividades criam nos sistemas naturais. Entretanto, ao mesmo tempo, o alcance global da indústria e do comércio significa que os impactos de nosso estilo de vida se fazem sentir em todos os cantos do planeta. Nossa espécie ameaça consumir e destruir o mundo natural em uma velocidade que excede, e muito, a capacidade de reconstrução do planeta. (p. 43-44)
\end{abstract}

É necessário, portanto, despertar a percepção do indivíduo quanto à urgência de uma mudança de postura da sociedade, mesmo porque "na verdade o êxito de cada um depende muito mais, hoje em dia, de saber trabalhar em equipe" (MAY, 1972, p. 43)

O despertar da consciência ambiental decorre do conhecimento a respeito de como a natureza se comporta, e de como o homem depende e pertence à natureza. Para Capra (2006b, p. 158), “[...] a maneira apropriada de nos aproximarmos da natureza para aprender acerca de sua complexidade e da sua beleza não é por meio da dominação e do controle, mas sim, por meio do respeito, da cooperação e do diálogo."

Neste sentido faz-se necessário propor uma mudança de paradigma na postura humana para com o meio ambiente, resgatando-se valores de que o homem é um elemento da natureza, e não seu dominador. A ecologia profunda vem, portanto, contribuir para o afastamento do pensamento antropocêntrico e o direcionamento dos esforços humanos para a percepção de que não podem 
procurar solucionar as questões ambientais sem o reconhecimento do '[...] valor intrínseco de todos os seres vivos" (CAPRA, 2006b, p. 26).

Para Callenbach (2006, p. 75), os problemas ecológicos enfrentados pela sociedade global são genuinamente problemas de valores, posto que os adultos em geral parecem carecer de um senso de reverência e mesmo pertencimento para com a natureza.

É necessário criar consciência acerca das consequências do uso desregrado dos recursos naturais, pois a proteção do meio ambiente é uma questão de sobrevivência e os problemas causados independem do país de origem. Eles podem atingir uma localidade específica ou toda a população. A poluição do ar, a contaminação de águas, o efeito estufa e tantas outras formas de dano ao meio ambiente acabam por ferir o direito de todos ao meio ambiente sadio e equilibrado.

O resgate de valores, contudo, perpassa pela redefinição das prioridades da sociedade. É primordial que o ser humano deixe de se preocupar apenas com sua sobrevivência e passe a valorizar todas as formas de vida no planeta (CALLEBACH, 2006, p. 75-76).

O autor explica que, antes de se ocupar de argumentos econômicos ou científicos, o movimento ambientalista se baseia em valores morais e estéticos acerca do que é certo ou mesmo satisfatório (CALLENBACH, 2006, p. 77), destacando que "Todos nós sofremos as consequências das decisões baseadas em valores".

Tais valores não são inéditos e tampouco uma exclusividade do movimento ambientalista. Muitas são as sociedades que adotam as premissas da sustentabilidade em seu processo de gestão. O pensamento indígena descrito por Armstrong (2006, p. 39-45), por exemplo, demonstra que ter comportamento em sintonia com o fluxo da natureza é inerente ao ser humano, e que a postura predatória adotada pela humanidade nos dias atuais tem pouca ligação com aquilo que é genuinamente a essência da vida.

Há de se destacar que a preocupação com a preservação ambiental transcende o conceito clássico de que o meio ambiente é composto apenas pelas questões ecológicas. Na atualidade, é necessário abordar a temática ambiental desde o ponto de vista social, de políticas pública, de justiça, de urbanismo, além das questões de cunho cultural.

Pelo que se apresenta, o resgate dos valores de proteção ambiental propicia uma formação mais ampla do profissional do Direito, o qual deve refletir acerca dos problemas da sociedade a partir destas premissas de pertencimento e respeito ao planeta.

A sociedade costuma enxergar os profissionais do Direito como pessoas cultas, dotadas de conhecimento técnico intangível para o senso comum. Não obstante, o acadêmico e futuro 
profissional do Direito deve ser capaz de abstrair os conceitos jurídicos e identificar na sociedade sua aplicação, pois sua missão é agir com ética e contribuir para a formação de uma sociedade mais justa e igualitária.

Neste sentido, observa-se a provocação para uma genuína modificação do ensino jurídico para que propicie aos acadêmicos um aprofundamento acerca das implicações sociais de sua atuação. Tal modificação poderá ocorrer com base na Ecoalfabetização, conceito que se passa a tratar no item subsequente.

\section{AS CONTRIBUIÇÕES DA ECOALFABETIZAÇÃo PARA UM NOVO ENSINO JURÍDICO}

Retomando-se a crítica ao ensino jurídico atual, observa-se que o maior empecilho ao cumprimento efetivo das determinações legais é a ausência de preocupação com a utilização dos conceitos e mecanismos desenvolvidos nas disciplinas de formação fundamental nas demais disciplinas do curso.

Para além da conexão das disciplinas de formação fundamental e técnica, é necessário repensar o ensino do Direito do posto de vista de sua contribuição social. A formação da cidadania compreende a interiorização de conceitos como a ética e o respeito pela sociedade.

Para além disto, há de se repensar o ensino jurídico também com vistas à formação de uma consciência ambiental global, mormente porque o acadêmico e o profissional do Direito são formadores de opinião pelo conhecimento que possuem.

A reponsabilidade social de uma conduta ética invoca a necessidade de uma formação que resgate os valores de vida em sociedade tratados no item anterior. Tais valores, por sua vez, podem ser melhor aprofundados em nível escolar por intermédio da Ecoalfabetização, conceito cunhado e desenvolvido por Fritjof Capra junto ao Centro de Ecoalfabetização, entidade sem fins lucrativos fundada pelo autor em 1995 e que se destina à formação humana para uma vida sustentável. (CAPRA, 2006a)

A obra oriunda do projeto encabeçado por Capra apresenta relatos das experiências vivenciadas por intermédio do Centro, destacando as profundas modificações sociais nos locais onde as escolas se abriram para o conceito da ecoalfabetização. 
Em que pese as experiências narradas no livro tenham ocorrido no âmbito da educação de crianças, observa-se que muito do que foi aplicado poderia ser transportado para a comunidade universitária com vistas a essa mudança de paradigma.

Uma iniciativa digna de destaque é justamente a propositura dos valores do movimento slow food para a educação, dando vida a um movimento slow school. A analogia feita por Holt (2006, p. 87-94) busca interiorizar no ensino os princípios norteadores do movimento que prega o consumo de alimentos preparados em casa, em contraposição à fast food combatida por muitos.

A slow school procura identificar a possibilidade de realização pessoal com a aquisição do conhecimento proporcionado no ambiente escolar. Permite uma maior gestão do aluno com relação aos projetos aos quais pretende aderir e uma verdadeira integração de conceitos da filosofia, tradição, comunidade e escolhas morais (Holt, 2006, p. 91).

Neste sentido, o movimento slow school permite uma integração genuína entre a teoria e a prática, levando o aluno a aplicar os conceitos teóricos na solução de questões da comunidade em que esteja inserido, em verdadeira conexão dos diferentes conhecimentos adquiridos durante o curso.

$\mathrm{Na}$ academia, a contribuição dos valores da slow school poderia justamente ser a maior integração do conteúdo de cunho ambiental com o de outras disciplinas, de forma que os estudantes pudessem procurar solucionar situações jurídicas reais.

A rigidez curricular faz com que as disciplinas sejam trabalhadas isoladamente, compartimento o conhecimento adquirido pelo acadêmico, o qual, por si só, talvez não consiga avaliar a amplitude dos conceitos estudados e sua inter-relação.

A educação ambiental voltada à sustentabilidade carece do trabalho de interiorização dos conceitos de respeito pelo planeta e pela sociedade, e pode ser implantada no curso superior como mais que apenas o cumprimento de uma determinação legal.

A Política Nacional de Educação Ambiental transfere às instituições de ensino o compromisso de integrar a educação ambiental aos programas que desenvolvem (Art. $3^{\circ}$ ), cabendo às instituições desenvolver estratégias para que os conteúdos sejam conexos, e não segmentados.

A ideia da slow school objetiva retirar a "camisa de força curricular" (HOLT, 2006, p.88) e permitir a avaliação do desempenho de maneira integrada. Quiçá a integração plena seja demasiadamente ousada para a estrutura já consolidada dos cursos de Direito. Não obstante, nada impede que docentes do mesmo semestre letivo elaborem projetos interdisciplinares de forma a apresentar ao futuro jurista a verdadeira abrangência dos conteúdos abordados em sala. 
A opção por um currículo abrangente e integrado não é tarefa fácil, e exige do docente maior dedicação e esforço no uso de "amplas estratégias de ensino" (HOLT, 2006, p. 87). Por outro lado, o compromisso que se assume ao optar pela dedicação à docência exige que o docente se renove e procure orientar seus alunos na busca pelo conhecimento.

É preciso romper o mito de que o conhecimento jurídico se produz na academia, pois a sociedade é quem de fato apresenta as necessidades e exige do jurista uma resposta para seus anseios. Para tanto, o ensino jurídico deve se destinar a desenvolver a autonomia do acadêmico, propiciando uma postura crítica com embasamento.

Segundo Paulo Freire (1996)

\begin{abstract}
A nossa capacidade de aprender, de que decorre a de ensinar, sugere ou, mais do que isso, implica a nossa habilidade de apreender a substantividade do objeto aprendido. A memorização mecânica do perfil do objeto não é aprendizado verdadeiro do objeto ou do conteúdo. Neste caso o aprendiz funciona muito mais como paciente da transferência do objeto ou do conteúdo do que como sujeito crítico, epistemologicamente curioso, que constrói o conhecimento do objeto ou participa de sua construção. É precisamente por causa desta habilidade de apreender a substantividade do objeto que nos é possível reconstruir um mal aprendizado, o em que o aprendiz foi puro paciente da transferência do conhecimento feita pelo educador. (p. 28)
\end{abstract}

A atual formatação do ensino jurídico, voltada em sua grande parte para a feitura de exames, deixa de contemplar o desenvolvimento do futuro egresso do curso. O bom desempenho em exames deve decorrer do profundo domínios dos conceitos apreendidos ao longo da formação acadêmica, não podendo ser um fim em si mesmo.

O desenvolvimento da autonomia do acadêmico de Direito pode ocorrer por intermédio de projetos interdisciplinares que permitam uma visão holística do fenômeno social. Assim, uma vez que o Direito Ambiental se socorre de outras áreas do Direito para sua efetiva aplicação, nada impediria uma atividade em alinhamento com a disciplina de Direito Civil, Direito Constitucional e Direito Penal.

Ainda, para além da disciplina de Direito Ambiental propriamente dita, é crucial compreender a amplitude a educação ambiental quanto à sustentabilidade e a vida em sociedade, o que poderia ser facilmente incorporado em disciplinas como Direito Tributário - em discussões acerca de extrafiscalidade - , Direito Trabalhista - em atenção ao ambiente do trabalho, Direito Empresarial - quanto à sustentabilidade das organizações, dentre outros.

Para Rodrigues (2014, p.6) 
A Educação Ambiental, como campo de conhecimento permeável e articulável em rede a outros tantos saberes, demanda movimentos de religação e associação do que está disjunto. Ela desponta como possibilidade de "reencantamento da educação" pela introdução de novos conhecimentos e novas metáforas oriundos do diálogo e da convergência de várias áreas do saber. Por ser portadora de novas sensibilidades e postura ética, sintonizada com o projeto de uma cidadania ampliada, a Educação Ambiental apresenta uma gama de possibilidades para o desenvolvimento de práticas pedagógicas mais solidárias e comprometidas com a emancipação humana.

Por fim, destaca-se que a mudança de paradigma no ensino jurídico deve partir do corpo docente em profundo alinhamento com a Instituição de Ensino Superior a que é vinculado. As mudanças mais significativas devem ocorrer de maneira democrática e sensata.

\section{CONSIDERAÇÕES FINAIS}

A preocupação com a proteção do meio ambiente deve estar presente nas mais diversas áreas da sociedade, pois, quando se fala em proteção ambiental, a questão adquire dimensão universal. Isto porque a preservação do Planeta, ainda que neste caso se esteja diante de uma visão puramente antropocêntrica, é premissa para a continuidade da sobrevivência da espécie humana na Terra. Não é mais possível conceber seres com formação dita superior que não tenham a capacidade mental de identificar tais problemas como centrais na sociedade contemporânea.

Por este motivo, em lugar de um Direito conservador e retrospectivo, comprometido ainda com valores privatistas típicos da sociedade patrimonialista, é necessário um novo paradigma jurídico, com vistas a um direito prospectivo e transformador, compromissado com as gerações futuras, preocupado com a melhoria da qualidade dos meios naturais e de vida.

Neste sentido, observa-se que a formação do profissional do Direito deve contemplar uma veia humanística, visando o desenvolvimento de um cidadão crítico e ético. Além disso, é primordial que o profissional da área jurídica tenha verdadeiro senso de cooperação, de pertencimento a um todo maior que ele e suas questões pessoais, de forma a de fato poder contribuir para a construção de uma sociedade mais justa e igualitária.

A Universidade precisa ser um local onde, além dos conhecimentos básicos e técnicos, o acadêmico se sinta compelido a realizar verdadeiras reflexões acerca das necessidades da sociedade em que está inserido, e que se veja como importante fator de mudança dessa mesma sociedade.

É necessário que as estratégias adotadas no curso de Direito visem mais do que apenas a feitura de provas, é imperioso que os critérios qualitativos sejam diversos dos resultados 
impostos por um modelo de avaliação que não leva em consideração a capacidade mental do examinando de solucionar problemas de maneira criativa e eficaz.

O ensino jurídico deve assumir um verdadeiro compromisso, portanto, com a formação de cidadãos, e não de meros aplicadores da legislação, porquanto para tanto já há, inclusive, softwares sendo desenvolvidos, através do qual se apresenta o caso concreto e se obtém, por intermédio de algoritmos, a incidência legislativa para a situação fática.

Os profissionais do Direito, portanto, não meros aplicadores da subsunção, devendo ser artistas da Ciência Jurídica, apresentando a solução que melhor se adequa ao caso concreto, ainda que tal solução não seja a mais óbvia, ou a diretamente expressa no texto da lei.

Para tanto, faz-se necessário resgatar os valores de conexão com a natureza, pois, se o Direito de aplica na sociedade, a sociedade se encontra encravada no meio ambiente. As discussões em nível de solução de problemas sociais não podem desconsiderar a relevância dos recursos naturais e sua imprescindibilidade para a manutenção da vida no planeta.

Por este motivo, é crucial o aprimoramento das estratégias de ensino jurídico para que haja verdadeira interdisciplinaridade, de forma que o acadêmico se veja verdadeiramente preparado para aplicar o Direito no mundo prático. Ainda, é imperioso que esta interdisciplinaridade transcenda até mesmo os limites da Ciência Jurídica, e busque, em outras áreas do conhecimento, ferramentas de gestão humana, porquanto o profissional do direito deve receber formação para agir dentro da sociedade.

Desta feita, tem-se que os postulados da educação ambiental devem inspirar o docente do curso de Direito à formação integral do acadêmico, proporcionando integração entre as disciplinas de formação fundamental e técnicas, de forma a desenvolver sua autonomia. Tal autonomia deve, em longo prazo, resultar na capacidade do profissional de solucionar as questões que lhe forem apresentadas com o respaldo de conhecimentos de diferentes áreas, com a genuína humildade científica de quem quer solucionar o problema, e não apenas ser o herói no caso concreto.

Nesta linha tem-se o conceito de Alfabetização Ecológica de Fritjof Capra, o qual tem o cunho de resgatar os valores de respeito à natureza para a formação de uma verdadeira cidadania ambiental. Cada ser humano é mais uma parte dessa bela teia da vida, e precisa se enxergar como uma peça do todo, sem se colocar acima da natureza ou de seus pares. Assim, a discussão proposta pelo presente trabalho confirma a possibilidade de utilização dos valores da Alfabetização Ecológica também no ensino jurídico, de forma a propiciar uma formação plena do acadêmico de Direito, com vistas a sua efetiva participação e contribuição para com a sociedade. 


\section{REFERÊNCIAS}

BRASIL. Constituição da República Federativa do Brasil de 1988. Disponível em http://www.planalto.gov.br/ccivil_03/Constituicao/Constituicao.htm Acesso em setembro de 2016.

BRASIL. Decreto no 4.281, de 25 de junho de 2002. Regulamenta a Lei no 9.795, de 27 de abril de 1999, que institui a Política Nacional de Educação Ambiental, e dá outras providências. Disponível em http://www.planalto.gov.br/ccivil_03/decreto/2002/d4281.htm Acesso em setembro de 2016.

BRASIL. Lei 9.795, de 27 de abril de 1999. Dispõe sobre a educação ambiental, institui a Política Nacional de Educação Ambiental e dá outras providências. Disponível em http://www.planalto.gov.br/ccivil_03/leis/L9795.htm Acesso em setembro de 2016.

BRASIL. Ministério da Educação. Resolução CNE/CES n ${ }^{\circ}$ 9, de 29 de setembro de 2004. Institui as Diretrizes Curriculares Nacionais do Curso de Graduação em Direito e dá outras providências. Disponível em http://portal.mec.gov.br/cne/arquivos/pdf/rces09_04.pdf Acesso em setembro de 2016.

CALLENBACH, Ernest. Valores. In: CAPRA, Fritjof et al. Alfabetização Ecológica: A educação das crianças para um mundo sustentável. São Paulo, Cultrix, 2006.

CAPRA, Fritjof. Et al. Alfabetização Ecológica: A educação das crianças para um mundo sustentável. Michael K. Stone e Zenobia Barlow, Org. São Paulo: Cultrix, 2006.

CAPRA, Fritjof. A Teia da Vida: Uma nova compreensão científica dos sistemas vivos. Trad. Newton Roberval Eichemberg. São Paulo: Cultrix, 2006.

GARBACCIO, Grace Ladeira; BANDEIRA, Gonçalo Nicolau Cerqueira Sopas de Mello; SIQUEIRA, Lyssandro Norton. DOGMAS AMBIENTAIS: A INDISCRIMINADA EXIGÊNCIA DE EIA/RIMA PARA ATIVIDADES POLUIDORAS: ESTUDOS BRASILEIRO, FRANCÊS E DA CONSTITUIÇÃO PORTUGUESA. Revista Juridica, [S.1.], v. 1, n. 58, p. 21 - 43, abr. 2020. ISSN 2316-753X. Disponível em: <http://revista.unicuritiba.edu.br/index.php/RevJur/article/view/3822/371372163>. Acesso em: 21 abr. 2020. doi:http://dx.doi.org/10.21902/revistajur.2316-753X.v1i58.3822. 
GOLEMAN, Daniel. Inteligência Ecológica: O impacto do que consumimos e as mudanças que podem melhorar o planeta. Trad. Ana Beatriz Rodrigues. Rio de Janeiro, Elsevier, 2011.

HOLTS, Maurice. A ideia da slow school: é hora de desacelerar a educação? In: CAPRA, Fritjof et al. Alfabetização Ecológica: A educação das crianças para um mundo sustentável. São Paulo, Cultrix, 2006.

MAY, Rolo. O home à procura de si mesmo. 33 ed. Petrópolis: Editora Vozes, 1972.

MORAIS DA ROSA, Alexandre; KHALED JR., Salah H. Saia da Matrix! A (De)formação jurídica como máquina de produção de cegueira normativa. Disponível em http://justificando.com/2014/08/05/saia-da-matrix-deformacao-juridica-como-maquina-de-producao -de-cegueira-normativa/ Acesso em setembro de 2016.

RODRIGUES, Ana Raquel de Souza. Educação ambiental em tempos de transição paradigmática: entrelaçando saberes "disciplinados". Ciênc. educ. (Bauru) [online]. 2014, vol.20, n.1, pp.195-206. Disponível em http://dx.doi.org/10.1590/1516-731320140010012 Acesso em agosto de 2016. 